\title{
Carbohydrate Metabolism of the Perfused Rat Liver
}

\author{
By B. D. ROSS, R. HEMS, R. A. FREEDLAND AND H. A. KREBS \\ Medical Research Council Unit for Research in Cell Metabolism, Department of Biochemistry, \\ University of Oxford
}

(Received 10 May 1967)

\begin{abstract}
1. The rates of gluconeogenesis from most substrates tested in the perfused livers of well-fed rats were about half of those obtained in the livers of starved rats. There was no difference for glycerol. 2. A diet low in carbohydrate increased the rates of gluconeogenesis from some substrates but not from all. In general the effects of a low-carbohydrate diet on rat liver are less marked than those on rat kidney cortex. 3. Glycogen was deposited in the livers of starved rats when the perfusion medium contained about $10 \mathrm{~mm}$-glucose. The shedding of glucose from the glycogen stores by the well-fed liver was greatly diminished by $10 \mathrm{~mm}$-glucose and stopped by 13.3 mM-glucose. Livers of well-fed rats that were depleted of their glycogen stores by treatment with phlorrhizin and glucagon synthesized glycogen from glucose. 4. When two gluconeogenic substrates were added to the perfusion medium additive effects occurred only when glycerol was one of the substrates. Lactate and glycerol gave more than additive effects owing to an increased rate of glucose formation from glycerol. 5. Pyruvate also accelerated the conversion of glycerol into glucose, and the accelerating effect of lactate can be attributed to a rapid formation of pyruvate from lactate. 6. Butyrate and oleate at $2 \mathrm{~mm}$, which alone are not gluconeogenic, increased the rate of gluconeogenesis from lactate. 7. The acceleration of gluconeogenesis from lactate by glucagon was also found when gluconeogenesis from lactate was stimulated by butyrate and oleate. This finding is not compatible with the view that the primary action of glucagon in promoting gluconeogenesis is an acceleration of lipolysis. 8. The rate of gluconeogenesis from pyruvate at $10 \mathrm{~mm}$ was only $70 \%$ of that at $5 \mathrm{~mm}$. This 'inhibition' was abolished by oleate or glucagon.
\end{abstract}

The procedure of rat liver perfusion developed in previous work (Hems, Ross, Berry \& Krebs, 1966; Ross, Hems \& Krebs, 1967) was used to study various aspects of carbohydrate metabolism in the liver. They concern the effect of the nutritional state on gluconeogenesis, the factors that regulate the deposition of glycogen versus release of glucose into the circulation, and the rates of gluconeogenesis in the presence of mixtures of substrates.

\section{METHODS}

The technique of perfusion and the analytical methods for the determination of metabolites were the same as in previous work (Hems et al. 1966; Ross et al. 1967). As a rule the results are expressed as means \pm s.E.M., with the numbers of observations in parentheses. Since it is not possible to measure rates of gluconeogenesis accurately when the liver contains large quantities of carbohydrate, the fed rats were treated with phlorrhizin and glucagon to deplete the liver of glycogen. Phlorrhizin (l g./kg. body wt.) was given subcutaneously as described by Krebs, Notton \& Hems (1967); at the same time glucagon (50 $\mu \mathrm{g} . / \mathrm{kg}$. body wt.) was injected intraperitoneally. This treatment decreased the glycogen content of the liver within $3 \mathrm{hr}$. to that of rats starved for $48 \mathrm{hr}$.

Solutions of oleate $(0.1 \mathrm{M})$ were freshly prepared by placing $1 \mathrm{~m}$-mole of the free fatty acid in a $10 \mathrm{ml}$. graduated test tube and adding water to give a total volume of $8.5 \mathrm{ml}$. The tube was heated to about $60^{\circ}$ and slightly more than $1 \mathrm{ml}$. of $\mathrm{N}-\mathrm{NaOH}$ was added dropwise while the tube contents were agitated on a Vortex mixer. The fatty acid dissolved after the addition of a small excess of alkali. The volume was then made up to $10 \mathrm{ml}$. The quantity of fatty acid solution to be added to the perfusion medium was placed in a test tube while still warm and $3 \mathrm{ml}$. of dialysed $25 \%$ bovine albumin solution was added with vigorous stirring. The $\mathrm{pH}$ of the mixture was adjusted to about $\mathbf{7 \cdot 4}$ by the addition of dil. HCl. This stock solution was added to the perfusion medium after a preliminary perfusion period of $38 \mathrm{~min}$. as previously described (Hems et al. 1966; Ross et al. 1967).

\section{RESULTS}

Effect of the nutritional state on the rate of gluconeogenesis in rat liver. Five different groups were 
tested: (1) rats fed on the standard rat cube diet (Oxoid Breeding Diet for Rats and Mice) and then starved for $48 \mathrm{hr}$., no other treatment; (2) as (1), followed by treatment with phlorrhizin and glucagon $3 \mathrm{hr}$. before perfusion; (3) well-fed rats maintained on the standard diet and treated with phlorrhizin and glucagon $3 \mathrm{hr}$. before perfusion; (4) rats fed on a diet low in carbohydrate and high in protein and fat, consisting of 3 parts of casein and 1 part of margarine, plus vitamin and mineral supplements (Krebs, Bennett, de Gasquet, Gascoyne \& Yoshida, 1963a), which induces an increased rate of gluconeogenesis in kidney-cortex slices after a few days; the rats were kept on this diet for 4 days and then treated with phlorrhizin and glucagon $3 \mathrm{hr}$. before perfusion; (5) rats given a diet containing a high content of glycerol $(60 \%$ glycerol, $40 \%$ rat cubes) for 4 days and treated with phlorrhizin and glucagon $3 \mathrm{hr}$. before perfusion.

The rates of glucose formation from lactate, serine, fructose, sorbitol and dihydroxyacetone in the livers of well-fed rats treated with phlorrhizin and glucagon were about half of those found in the livers of rats starved for $48 \mathrm{hr}$. With glycerol as substrate there was no difference between the well-fed and the starved state (Table 1).

Treatment with phlorrhizin and glucagon had no effect on the rates of glucose formation from lactate and the other precursors tested in the livers of rats starved for $48 \mathrm{hr}$.

The livers of rats kept on the casein-margarine diet gave higher rates of glucose formation from lactate, glycerol and dihydroxyacetone than the livers of rats fed on the standard diet, but they were hardly significantly different for fructose and glutamate. With lactate the rate was the same as that found after starvation for $48 \mathrm{hr}$., whereas with glycerol it appeared slightly higher and with dihydroxyacetone somewhat lower than in the starved rats. Glycerol was the only substrate that tended to give higher rates of gluconeogenesis in the livers of rats fed on the casein-margarine diet compared with $48 \mathrm{hr}$. starvation but the significance of this effect is doubtful. It was thought that the higher rates might be induced by the glycerol derived from the degradation of neutral fat, and rats were therefore given the diet containing $60 \%$ glycerol. However, in this group, the rate of gluconeogenesis $(0 \cdot 82 \pm 0 \cdot 11 \mu \mathrm{mole} / \mathrm{min}$./g. wet wt., 11 observations) was only slightly higher than in the group fed on casein-margarine. The effects of the low-carbohydrate diet on gluconeogenesis in the liver were much less marked than those obtained by Krebs et al. (1963a) in kidney cortex.

Glycogen synthesis in the perfused rat liver. When no glucose is added to the perfusion medium, no glycogen is formed by the starved liver from gluconeogenic precursors, glucose being the only major product of gluconeogenesis (see Hems et al. 1966). Only when the perfusion medium contains $10 \mathrm{~mm}$ or more glucose are appreciable amounts of glycogen deposited in the liver (Sokal, Miller \& Sarcione, 1958; Gordon, 1963). This was confirmed in the present experiments. To determine the glycogen content, liver lobes were removed at 5 and $135 \mathrm{~min}$. When livers of rats starved for $48 \mathrm{hr}$. were perfused with $13.3 \mathrm{~mm}$-glucose, glycogen deposition was slight and irregular, the rate being $0.25 \pm 0.20$ (4) $\mu$ mole of glucose equiv./min./g. wet wt. With $13.3 \mathrm{~mm}$-glucose plus $10 \mathrm{~mm}$-lactate in the medium, the overall rate of carbohydrate synthesis between $40 \mathrm{~min}$. and $130 \mathrm{~min}$. was the same as that of lactate alone $[0.94 \pm 0.11$ (4) $\mu \mathrm{mole} / \mathrm{min} . / \mathrm{g}$. wet wt.], and of this $0.22 \pm 0.07 \mu$ mole was glycogen. The rate of lactate removal was identical in the presence of $13.3 \mathrm{~mm}$-glucose $[1.93 \pm 0.27$ (4) $\mu \mathrm{moles} / \mathrm{min} . / \mathrm{g}$. $]$

Table 1. Effect of the nutritional state on the rate of glucose synthesis in the perfused rat liver

For the composition of the diets and the treatment of the animals see the text. Substrates were added at $38 \mathrm{~min}$. Results are the means \pm S.E.M. of the numbers of experiments given in parentheses.

Glucose formed ( $\mu$ moles/min./g. wet wt.)

Treatment

Nutritional state $\quad \ldots \quad \ldots$

Substrate added (10 mm)

Nil

L-Lactate

L-Serine

Glycerol

Dihydroxyacetone

D-Fructose

Sorbitol

L-Glutamate
None

Starved $48 \mathrm{hr}$.

$0 \cdot 14 \pm 0.03(5)$

$1.06 \pm 0.09$ (12)

$0.98 \pm 0.04(3)$

$0.48 \pm 0.08$ (5)

$2 \cdot 07 \pm 0 \cdot 30(6)$

$2 \cdot 68 \pm 0.25$ (4)

$1 \cdot 79 \pm 0.06(3)$

$0.31 \pm 0.04(6)$
Injection of phlorrhizin and glucagon

Low-carbohydrate,
$0 \cdot 10 \pm 0 \cdot 04(3)$

$1 \cdot 01 \pm 0 \cdot 06(5)$

$0 \cdot 50 \pm 0 \cdot 07(3)$

$2 \cdot 50 \pm 0 \cdot 17(3)$

$1 \cdot 70 \pm 0 \cdot 17(3)$
Starved $48 \mathrm{hr}$.

\section{Well-fed}

$0 \cdot 10 \pm 0 \cdot 07(4)$

$0.46 \pm 0.09(4)$

$0.40 \pm 0.08(3)$

$0.55 \pm 0.05(3)$

$0 \cdot 84 \pm 0 \cdot 17(3)$

$1 \cdot 70 \pm 0 \cdot 27(3)$

$1 \cdot 10 \pm 0 \cdot 07(3)$

$0 \cdot 22 \pm 0.09(3)$ high-protein-fat diet

$1 \cdot 07 \pm 0 \cdot 18(3)$

$0 \cdot 70 \pm 0 \cdot 14(3)$

$1 \cdot 23 \pm 0.13$ (3)

$1 \cdot 37 \pm 0.25(3)$

$0 \cdot 30 \pm 0 \cdot 02(4)$ 
and in its absence $[1.95 \pm 0.23$ (12) $\mu$ moles $/ \mathrm{min} . / \mathrm{g}$. $]$. Thus added glucose had no effect on gluconeogenesis from lactate in the starved rat except to direct part of the product to glycogen.

Metabolic behaviour of glycogen in the livers of well-fed rats. As Sokal et al. (1958) and Sokal, Sarcione \& Henderson (1964) have shown, the liver of the well-fed rat when perfused with rat blood sheds glucose unless the concentration in the medium is $10 \mathrm{~mm}$ or higher. At this glucose concentration in the perfusing medium the tissue glycogen remains fairly constant (see also Sokal \& Weintraub, 1966). In the present experiments (Table 2), which differ from those of the authors quoted (who used a semi-synthetic medium containing initially less than $0.3 \mathrm{~mm}$-glucose), much of the liver glycogen appeared as glucose in the medium within $60 \mathrm{~min}$. In an experiment recorded in Table 2, about $700 \mu$ moles of glucose were found in the medium, which was about $60 \%$ of the original glycogen content ( $1100 \mu$ moles) of the whole liver. Addition to the medium of $10 \mathrm{~mm}$-glucose greatly diminished the shedding of glucose but did not completely prevent it. With $13.3 \mathrm{~mm}$-glucose there was virtually no increase of glucose in the medium.

Table 2. Effect of glucose concentration in the medium on glucose shedding by the perfused liver of well-fed rats

Livers were perfused with $150 \mathrm{ml}$. of the standard medium containing variable concentrations of glucose. The values are averages of two observations. Liver samples taken at 0 , 60 and $120 \mathrm{~min}$. and analysed for glycogen showed no significant differences.

\begin{tabular}{|c|c|c|c|c|}
\hline \multirow{2}{*}{$\begin{array}{c}\text { Glucose } \\
\text { added } \\
(\mathbf{m M})\end{array}$} & \multicolumn{3}{|c|}{$\begin{array}{l}\text { Glucose found in total medium } \\
\text { ( } \mu \text { moles })\end{array}$} & \multirow{2}{*}{$\begin{array}{c}\text { Change of } \\
\text { glucose in } \\
\text { medium } \\
\text { ( } \mu \text { moles) }\end{array}$} \\
\hline & $0 \mathrm{~min}$. & $60 \mathrm{~min}$. & $120 \mathrm{~min}$. & \\
\hline 0 & 30 & 705 & 650 & +620 \\
\hline $6 \cdot 7$ & 1050 & 1210 & 1130 & +80 \\
\hline 10 & 1395 & 1590 & 1480 & +85 \\
\hline $13 \cdot 3$ & 2115 & 2210 & 1950 & -165 \\
\hline
\end{tabular}

After $2 \mathrm{hr}$. there was a small decrease of glucose in the medium but no measurable increase in the glycogen content.

Glycogen synthesis from glucose occurred in the livers of well-fed rats when the rats were treated with phlorrhizin and glucagon $3 \mathrm{hr}$. before the start of perfusion. Within $3 \mathrm{hr}$. after treatment, the glycogen content had fallen to the amount in the liver of rats starved for $48 \mathrm{hr}$. The livers were perfused with a medium containing $13.3 \mathrm{~mm}$-glucose and samples of the tissue were removed after 5, 40 and $135 \mathrm{~min}$. Glycogen (expressed as glucose) was synthesized at a rate of $0.75 \mu \mathrm{mole} / \mathrm{min}$. $/ \mathrm{g}$. and the glucose uptake from the medium was at a similar rate $(0 \cdot 65 \mu \mathrm{mole} / \mathrm{min} . / \mathrm{g}$.).

When glucose $(13.3 \mathrm{~mm})$ and lactate $(10 \mathrm{~mm})$ were added together, glycogen synthesis occurred at the rate of $0.44 \mu \mathrm{mole} / \mathrm{min}$./g. (Table 3). The rate of glucose uptake was about the same $(0.41 \mu \mathrm{mole} /$ min./g.), but the rate of lactate uptake was low $(0.42 \mu \mathrm{mole} / \mathrm{min} . / \mathrm{g}$.$) , less than half of the rate of$ lactate removal with lactate alone. The amount of lactate plus glucose removed exceeded that of glycogen formed in these experiments. Thus whereas the lactate utilized when added as sole substrate was accounted for as glucose, the lactate removed in the presence of glucose underwent reactions other than gluconeogenesis (Table 3). This is in contrast with the behaviour of livers of starved rats where, as already stated, glucose had no effect on the metabolic fate of lactate.

Gluconeogenesis from substrate combinations. Ross et al. (1967) showed that, in general, simultaneous addition of two gluconeogenic substrates, e.g. glutamate plus pyruvate, glutamate plus oxaloacetate or mixtures of amino acids gave no higher rates of gluconeogenesis than the more rapidly reacting component of the mixture, except when glycerol was one of the substrates. This is illustrated in Table 4. The calculation of the additive effects of substrate combinations raises the question of how the endogenous glucose formation is affected by the addition of substrates. There is no precise information on this point. It is possible that the added

Table 3. Glucose and glycogen formation in perfused livers from well-fed rats treated with phlorrhizin and glucagon

Glucose was added at $0 \mathrm{~min}$. and L-lactate $(10 \mathrm{~mm})$ at $38 \mathrm{~min}$. For details of treatment and liver sampling see the text. The metabolic changes are means \pm s.E.M. of the numbers of observations given.

\begin{tabular}{|c|c|c|c|c|c|c|}
\hline $\begin{array}{c}\text { Glucose } \\
\text { added } \\
(\mathrm{mM})\end{array}$ & $\begin{array}{l}\text { Lactate } \\
\text { added } \\
(\mathrm{mm})\end{array}$ & $\begin{array}{c}\text { No. of } \\
\text { observations }\end{array}$ & $\begin{array}{c}\text { Change of } \\
\text { glucose } \\
\text { ( } \mu \mathrm{mole} / \mathrm{min} . / \mathrm{g} .)\end{array}$ & $\begin{array}{c}\text { Change of } \\
\text { glycogen } \\
(\mu \mathrm{mole} / \mathrm{min} . / \mathrm{g} .)\end{array}$ & $\begin{array}{l}\text { Change of total } \\
\text { carbohydrate } \\
\text { ( } \mu \text { mole/min./g.) }\end{array}$ & $\begin{array}{c}\text { Change of } \\
\text { lactate } \\
\text { ( } \mu \text { moles/min./g.) }\end{array}$ \\
\hline $\mathbf{0}$ & $\mathbf{0}$ & 3 & $-0.10 \pm 0.04$ & & $+0 \cdot 10$ & \\
\hline $13 \cdot 3$ & 0 & 4 & $-0.65 \pm 0.11$ & $+0.75 \pm 0.12$ & $+0 \cdot 10$ & \\
\hline $\mathbf{0}$ & 10 & 4 & $+0.46 \pm 0.09$ & & +0.46 & -1.02 \\
\hline $13 \cdot 3$ & 10 & 4 & $-0.41 \pm 0.20$ & $+0.44 \pm 0.09$ & +0.03 & $-0.42 \pm 0.06$ \\
\hline
\end{tabular}


Table 4. Gluconeogenesis from substrate combinations in the perfused rat liver

The value for $10 \mathrm{~mm}$-pyruvate is taken from Ross et al. (1967). The 'expected additive rate' was calculated by adding the rates observed for one single substrate and rate(s) of the increment(s) over the control. This procedure is based on the assumption that the endogenous glucose formation continues on the addition of precursors. In the experiments with $3 \mathrm{~mm}$-pyruvate, its concentration was approximately maintained by continuous addition, as described in the text. Results are the means \pm S.E.M. of the numbers of experiments given in parentheses.

Rate of gluconeogenesis ( $\mu$ moles/min./g. fresh wt.)

Substrates added (initial concn.)

None

Glycerol (5 mM)

Glycerol (10 mM)

Pyruvate (5 mm)

Pyruvate (10 mM)

Pyruvate (3 mM)

Glutamate ( $5 \mathrm{~mm})$

Glutamate (10 mM)

Pyruvate (5 mM)-glycerol (5 mM)

Pyruvate (10 mM)-glycerol (10 mM)

Glutamate (5 mM)-glycerol (5 mM)-pyruvate ( $5 \mathrm{~mm}$ )

Glutamate (10 mM)-glycerol (10 mM)

L-Lactate (10 mM)-pyruvate (10 mM)

L-Lactate (10 mM)-pyruvate (3 mM)

L-Lactate (10 mM)-glycerol (10 mM)

Rate of gluconeogenesis ( $\mu$ moles

\section{Observed}

$0 \cdot 14 \pm 0 \cdot 03(5)$

$0.33 \pm 0.04(4)$

$0 \cdot 48 \pm 0.03(5)$

$1.58 \pm 0.02(4)$

$1.02 \pm 0.08(5)$

$1.27 \pm 0.02(4)$

$0 \cdot 16 \pm 0 \cdot 17(3)$

$0 \cdot 31 \pm 0.04(6)$

$1.98 \pm 0.20(4)$

$1 \cdot 63 \pm 0.20(7)$

$2 \cdot 06 \pm 0 \cdot 15(5)$

$0.61 \pm 0.09(6)$

$0.95 \pm 0.09(4)$

$1 \cdot 41 \pm 0 \cdot 12(4)$

$1.94 \pm 0.02(7)$
Increment
over control

Expected additive rate

0.19
0.34
1.44
0.88
1.13
0.02
0.17
1.84
1.49
1.92
0.47
0.81
1.27
1.80
$1 \cdot 77$

$1 \cdot 36$

$1 \cdot 93$

0.50

$1 \cdot 94$

$2 \cdot 19$

$1 \cdot 40$ substrate suppresses gluconeogenesis from endogenous sources; if this were the case, the endogenous glucose formation should be ignored in calculating the expected additive rates of gluconeogenesis. Another possibility is that gluconeogenesis from endogenous sources is constant, irrespective of the added substrate. In this case the expected rate of gluconeogenesis from substrate combination would be the sum of the endogenous rate plus the increments above the endogenous rates observed with the various substrates. The calculations obtained on this latter assumption are included in Table 4. Whatever calculation is used, the results indicate that the rates in the presence of glycerol plus glutamate were approximately additive. Lactate plus glycerol, however, yielded more glucose than expected on the basis of mere additive effects and, for pyruvate plus glycerol, there is a suggestion that the yields may be greater than those of additive effects. Additive effects of glycerol with various other substrates (lactate, pyruvate, fumarate, succinate, $\alpha$-oxoglutarate, glutamate, proline and ornithine) have already been reported by Krebs, Hems \& Gascoyne (1963b) for gluconeogenesis in slices of rat kidney cortex.

To elucidate the nature of the increases beyond the expected additive effects of the substrate combination glycerol plus lactate, the rates of removal of lactate and of glycerol were measured and compared with those of the formation of glucose. As shown in Table 5, the rates of lactate removal in the presence of glycerol were about the same as those previously found without glycerol (Ross et al. 1967), and at $90 \mathrm{~min}$. about 1 molecule of lactate had disappeared per molecule of glucose formed, in contrast with the ratio 2 observed when lactate was the only added substrate. The rate of glycerol removal $(2.70 \mu \mathrm{moles} / \mathrm{min} . / \mathrm{g}$.) was more rapid in the presence of lactate than in its absence (1.02 $\mu \mathrm{moles} /$ min./g.) and the extra glucose formed above the expected additional effects was thus derived from glycerol. In other words, lactate stimulated the conversion of glycerol into glucose. Somewhat less glucose was found than expected on the assumption that all lactate and glycerol removed were converted into glucose. The difference was probably due to the combustion of some lactate or glycerol. Similar experiments with the substrate combination pyruvate plus glycerol (Table 6) showed that pyruvate contributed less than half of the carbon of glucose, at $60 \mathrm{~min} ., 464 \mu \mathrm{moles}$ having come from pyruvate and $666 \mu \mathrm{moles}$ from glycerol. The difference between the amounts of glucose found and expected in this experiment were within the limits of error. This implies that virtually all the glycerol and pyruvate removed was recovered as glucose and that pyruvate promoted gluconeogenesis from glycerol.

Table 4 also shows the effects of the concentration of substrates on the rate of gluconeogenesis. With glycerol and glutamate the rate increased when the concentration of the substrate changed from 5 to $10 \mathrm{~mm}$ whereas with pyruvate the rate at $10 \mathrm{~mm}$ 
Table 5. Metabolic changes in rat liver perfused with lactate $(10 \mathrm{mM})$ and glycerol $(10 \mathrm{mM})$

Signs + and - refer to formation or removal respectively. Glucose formation has been corrected for the small blank found without added substrate. 'Glucose expected' was calculated on the assumption that all glycerol removed and all lactate not recovered as pyruvate were converted into glucose. The rats were starved for $48 \mathrm{hr}$.

Rates of changes between Overall changes at $90 \mathrm{~min}$. 30 and $60 \mathrm{~min}$. ( $\mu$ moles $/ \mathrm{min} . / \mathrm{g}) \quad.(\mu$ moles in total medium)

\begin{tabular}{|c|c|c|c|c|}
\hline Substrate & Expt. 1 & Expt. 2 & Expt. 1 & Expt. 2 \\
\hline Lactate & $-2 \cdot 79$ & -1.89 & -1003 & -708 \\
\hline Pyruvate & +0.89 & +0.09 & $+\quad 44$ & +57 \\
\hline Glycerol & $-2 \cdot 70$ & $-2 \cdot 44$ & -1350 & -1017 \\
\hline Glucose, found & +1.90 & $+1 \cdot 82$ & +1019 & +787 \\
\hline Glucose, expected & $+2 \cdot 30$ & $+2 \cdot 12$ & +1154 & +834 \\
\hline
\end{tabular}

Table 6. Metabolic changes in rat liver perfused with pyruvate (5 $\mathrm{mM})$ and glycerol $(5 \mathrm{mM})$

At the time when the overall changes were measured $(60 \mathrm{~min}$.$) , all added pyruvate and glycerol had disappeared.$ Signs + and - indicate formation or removal respectively. Glucose formation has been corrected for the small blank found without added substrate. 'Glucose expected' was calculated on the assumption that all glycerol removed and all pyruvate not recovered as lactate were converted into glucose. The rat was starved for $48 \mathrm{hr}$.

$\begin{array}{cc}\begin{array}{c}\text { Rates of change } \\ \text { during first } 20 \mathrm{~min} . \\ \text { of the addition } \\ \text { of substrates }\end{array} & \begin{array}{c}\text { Overall changes } \\ \text { at } 60 \text { min. }\end{array} \\ \begin{array}{c}(\mu \text { moles/min./g. } \\ \text { wet wt.) }\end{array} & \begin{array}{c}\mu \text { moles in } \\ \text { total medium })\end{array} \\ -3.81 & -618 \\ -2.26 & -666 \\ +2.69 & +154 \\ +1.78 & +595 \\ +1.69 & +565\end{array}$

was only two-thirds of that at 5mM. Higher concentrations of pyruvate are thus inhibitory. This 'inhibition' was not reversed by the addition of 10 mM-lactate. Experiments with still lower concentrations of pyruvate ( $3 \mathrm{~mm}$ ) are difficult to carry out satisfactorily because of the rapid removal of pyruvate. In an experiment in which $0.5 \mathrm{ml}$. of 2M-pyruvate was added to the medium every $20 \mathrm{~min}$. and a concentration of approx. $3 \mathrm{~mm}$ was maintained, the rate of gluconeogenesis was $1.27 \mu \mathrm{moles} / \mathrm{min}$./g. wet wt. This is higher than the rate at $10 \mathrm{~mm}$ but lower than that at $5 \mathrm{~mm}$.

A special case of substrate combinations is that of mixtures consisting of lactate and a fatty acid which by itself is not gluconeogenic. Butyrate $(2 \mathrm{~mm})$ or oleate $(2 \mathrm{~mm})$ increased the rate of gluconeogenesis from lactate (Table 7), as they do in rat kidney cortex. As Krebs, Speake \& Hems (1965) have pointed out, this effect can be due to a sparing action or activation of pyruvate carboxylase (or both) by acetyl-CoA derived from the fatty acids. Gluconeogenesis from 5mM-pyruvate was not accelerated by oleate, but at $10 \mathrm{~mm}$-pyruvate (when the rate was lower than at $5 \mathrm{~mm}$ ) oleate increased the rate.

Higher concentrations of butyrate $(5 \mathrm{~mm}$ and $10 \mathrm{~mm}$ ) abolished the stimulating effect of $2 \mathrm{mM}$ butyrate. Acetoacetate had no significant effect on the gluconeogenesis from lactate, in contrast with its action in kidney cortex. This is not unexpected because acetoacetate does not form acetyl-CoA in the liver (Mahler, 1953). Hence it can neither activate pyruvate carboxylase nor provide a substrate for the tricarboxylic acid cycle.

Effect of glucagon. According to Table 7 the effects of glucagon and fatty acids (butyrate and oleate) on the rate of gluconeogenesis from lactate are essentially additive. This is not compatible with the view (Struck, Ashmore \& Wieland, 1965, 1966; see also Williamson, Wright, Malaisse \& Ashmore, 1966) that the primary effect of glucagon is an acceleration of lipolysis by activation of lipases and that the increased gluconeogenesis is due to an increased concentration of fatty acids.

The magnitude of the glucagon effect in the presence of lactate alone, or lactate plus butyrate, or lactate plus oleate was remarkably similar. In the presence of pyruvate there was an accelerating effect of glucagon at $10 \mathrm{~mm}$ - but not at $5 \mathrm{~mm}$-pyruvate (where the rate without glucagon is higher than at $10 \mathrm{~mm})$. This suggests that glucagon abolishes inhibition of gluconeogenesis by higher concentrations of pyruvate. In other words, the point of attack of glucagon may be a step that is inhibited by $10 \mathrm{~mm}$-pyruvate.

\section{DISCUSSION}

Nutritional state and gluconeogenesis. That the gluconeogenic capacity of the whole organism is 


\section{Table 7. Effects of fatty acids and glucagon on the rate of gluconeogenesis from lactate and pyruvate in the perfused rat liver}

The concentration of glucagon (crystalline, Eli Lilly and Co., Indianapolis, Ind., U.S.A.) was $0.5 \mathrm{or} 1 \mu \mathrm{g} . / \mathrm{ml}$. No differences in effects between these concentrations were found. Glucagon was added at the same time as the other substrates after a preliminary period of perfusion of $38 \mathrm{~min}$. The substrate concentrations given in the Table are those in the perfusion medium immediately after addition. For comparison see values for pyruvate ( $10 \mathrm{~mm}$ and $5 \mathrm{~mm})$ in Table 4. n.s., Not significant. Results are given as means \pm s.E.M. of the numbers of experiments given in parentheses.

Rate of gluconeogenesis ( $\mu$ moles/min./g.)

Substances added

\begin{tabular}{|c|}
\hline $\begin{array}{l}\text { L-Lactate }(10 \mathrm{~mm}) \\
\text { L-Lactate }(10 \mathrm{~mm}) \text {-glucagon } \\
\text { L-Lactate }(10 \mathrm{~mm}) \text {-butyrate }(2 \mathrm{~m} \\
\text { L-Lactate }(10 \mathrm{~mm}) \text {-butyrate }(5 \mathrm{~m} \\
\text { L-Lactate }(10 \mathrm{~mm}) \text {-butyrate }(10 \mathrm{n} \\
\text { L-Lactate }(10 \mathrm{~mm}) \text {-butyrate }(2 \mathrm{~m} \\
\text { L-Lactate }(10 \mathrm{~mm}) \text {-oleate }(2 \mathrm{~mm}) \\
\text { L-Lactate }(10 \mathrm{~mm}) \text {-oleate }(2 \mathrm{~mm}) \text { - } \\
\text { L-Lactate }(10 \mathrm{~mm}) \text {-acetoacetate } \\
\text { L-Lactate }(5 \mathrm{~mm}) \\
\text { L-Lactate }(5 \mathrm{~mm}) \text {-glucagon } \\
\text { L-Lactate }(5 \mathrm{~mm}) \text {-butyrate }(2 \mathrm{~mm} \\
\text { Pyruvate }(10 \mathrm{~mm}) \text {-glucagon } \\
\text { Pyruvate }(10 \mathrm{~mm}) \text {-oleate }(2 \mathrm{~mm}) \\
\text { Pyruvate }(5 \mathrm{~mm}) \text {-glucagon } \\
\text { Pyruvate }(5 \mathrm{~mm}) \text {-oleate }(2 \mathrm{~mm})\end{array}$ \\
\hline
\end{tabular}

\begin{tabular}{|c|c|c|}
\hline Observed & $\begin{array}{c}\text { Increment over } \\
\text { lactate or pyruvate }\end{array}$ & $\begin{array}{l}\text { Increment due } \\
\text { to glucagon }\end{array}$ \\
\hline \multicolumn{3}{|l|}{$1.06 \pm 0.09(12)$} \\
\hline $1.86 \pm 0.16(8)$ & $0 \cdot 80$ & $0 \cdot 80$ \\
\hline $1.41 \pm 0.09(4)$ & $0 \cdot 35$ & \\
\hline $1 \cdot 15$ & n.s. & \\
\hline $1 \cdot 02 \pm 0 \cdot 17(4)$ & n.s. & \\
\hline $2 \cdot 20 \pm 0 \cdot 10(4)$ & $1 \cdot 14$ & $0 \cdot 79$ \\
\hline $1.59 \pm 0.12(4)$ & 0.53 & \\
\hline $2 \cdot 32 \pm 0.15(4)$ & $1 \cdot 26$ & $0 \cdot 73$ \\
\hline \multicolumn{3}{|l|}{$1.25 \pm 0.70(8)$} \\
\hline \multicolumn{3}{|l|}{$1.07 \pm 0.07(4)$} \\
\hline $1 \cdot 62 \pm 0 \cdot 11(4)$ & 0.55 & 0.55 \\
\hline $1 \cdot 17 \pm 0.03(3)$ & n.s. & \\
\hline $1.44 \pm 0.11(4)$ & $0 \cdot 42$ & 0.42 \\
\hline $1.45 \pm 0.06(3)$ & $0 \cdot 43$ & \\
\hline $1.41 \pm 0.11(4)$ & n.s. & \\
\hline $1.55 \pm 0.18(3)$ & n.s. & \\
\hline
\end{tabular}

lower in the well-fed state than under conditions where the supply of glucose is decreased (as in starvation or as a result of diets low in carbohydrate) has long been recognized (see Peters \& Van Slyke, 1946). The present results on the perfused liver indicate that the adaptive changes favouring gluconeogenesis are, per unit weight, greater in kidney cortex than in the liver. Precursors that react more slowly in the liver of well-fed than of starved rats include lactate, serine, dihydroxyacetone, fructose and sorbitol, whereas the rate of gluconeogenesis from glycerol was not affected by the nutritional state. Such differences in the response of substrates can be accounted for by the differences in the rate-limiting steps, which for lactate and serine include pyruvate carboxylase, and for glycerol is probably glycerol kinase and the $\alpha$-glycerophosphate dehydrogenases. Other factors that can control the rate of gluconeogenesis from various substrates have been discussed by Krebs (1964), Newsholme \& Underwood (1966) and Underwood \& Newsholme $(1966 a, b)$.

Deposition of glycogen in the liver. The perfused liver appears to regulate the interconversion of the glycogen as expected on the basis of the information on the intact animal. A low concentration of glucose in the perfused medium causes shedding of liver glycogen and a high concentration of glucose in the medium causes a deposition of glycogen in the tissue. Under the test conditions the critical concentration was of the order of $10 \mathrm{~mm}$, which is somewhat higher than the critical concentration in the intact animal (5-6 mM). Factors that are likely to determine the critical concentration are the activities of key enzymes such as glucokinase (EC 2.7.1.2), glycogen synthase (UDP-glucoseglycogen $\alpha$-4-glucosyltransferase, EC 2.4.1.11) and phosphorylase, which in turn are regulated by glucagon, glucose 6-phosphate and other factors. It is not surprising that the critical concentrations are therefore not identical in the perfused organ and in the living rat. When phlorrhizin is injected, the physiological state may be expected to be deranged in a major way. The rapid urinary excretion of glucose is probably followed by a continuous secretion of glucagon that stimulates the shedding of glucose by the liver (see Miller, 1961 ; Mortimore, 1963; Sokal et al. 1964).

Additive effects in the presence of glycerol. Additive effects with glycerol are to be expected if the stages between triose phosphate and glucose are not ratelimiting. In this case the triose phosphate arising from glycerol via $\alpha$-glycerol phosphate from other precursors such as lactate would not interfere with their conversion into glucose. That the capacity of the liver to convert triose phosphate into glucose is much higher than is required for the gluconeogenesis from lactate or glycerol is shown by the fact that 
dihydroxyacetone forms glucose much more rapidly than lactate or glycerol.

Stimulation of gluconeogenesis from glycerol by lactate and pyruvate. An explanation of the observed stimulation of gluconeogenesis from glycerol by lactate and pyruvate can be based on the assumption that the rate-limiting factor in the gluconeogenesis from glycerol is the conversion of $\alpha$-glycerophosphate into dihydroxyacetone phosphate. This assumption is justified because loading the liver with glycerol causes a large accumulation of $\alpha$-glycerophosphate in the tissue (D. H. Williamson, personal communication). $\alpha$-Glycerophosphate is converted into dihydroxyacetone phosphate either by the flavoprotein-linked mitochondrial dehydrogenase or by the NAD-linked cytoplasmic dehydrogenase. The activity of the latter depends, among other things, on the rate of regeneration of NAD from $\mathrm{NADH}_{2}$. This in turn depends on a suitable hydrogen acceptor, pyruvate being by far the most effective cytoplasmic acceptor. A dismutation between $\alpha$-glycerophosphate and added pyruvate would thus explain the stimulation of glycerol metabolism by pyruvate. On the addition of lactate, large quantities of pyruvate accumulate (see Table 5); the stimulating effect of the addition of lactate on glycerol metabolism can therefore also be explained by a dismutation with pyruvate.

Effects of fatty acids. The stimulation of gluconeogenesis from lactate by butyrate and oleate is analogous to effects observed in kidney-cortex slices (Krebs et al. 1965). In kidney slices it was difficult to establish how much of the stimulating effect of the fatty acids was due to the activation of pyruvate carboxylase through acetyl-CoA (Utter \& Keech, 1963) and how much to the sparing action of the fatty acids. Since in the perfused glycogen-depleted liver lactate is not a substrate of respiration but is quantitatively converted into glucose (Ross et al. 1967), the stimulating effects of the fatty acids cannot be ascribed to a sparing action and must therefore be attributed to the activation of pyruvate carboxylase.

Gluconeogenesis from pyruvate. The interpretation of the variations in the rate of gluconeogenesis observed in the presence of pyruvate offers difficulties because higher concentrations of pyruvate are inhibitory, the rate at $10 \mathrm{~mm}$ being only about twothirds of that at $5 \mathrm{~mm}$. The inhibition by $10 \mathrm{~mm}$-pyruvate was virtually abolished by either glucagon or by oleate. In kidney-cortex slices gluconeogenesis from pyruvate was not accelerated by fatty acids, presumably because the rapid degradation of pyruvate in that tissue saturated the tissue with acetyl-CoA. It is therefore unexpected to find an acceleration of the rate of gluconeogenesis from pyruvate by oleate in the perfused liver. The analysis of this effect requires further investigation.

This work was supported by U.S. Public Health Service Grant no. AM08715. The authors are indebted to Dr $O$. Behrens, Eli Lilly Co., Indianapolis, Ind., U.S.A., for a gift of glucagon. R.A.F. was in receipt of a U.S. Public Health Service Senior Postdoctoral Fellowship, on leave from the University of California, Davis, Calif., U.S.A.

\section{REFERENCES}

Gordon, E. R. (1963). Canad. J. Biochem. 41, 1611.

Hems, R., Ross, B. D., Berry, M. N. \& Krebs, H. A. (1966). Biochem. J. 101, 284.

Krebs, H. A. (1964). Proc. Roy. Soc. B, 159, 545.

Krebs, H. A., Bennett, D. A. H., de Gasquet, P., Gascoyne, T. \& Yoshida, T. (1963a). Biochem. J. 86, 22.

Krebs, H. A., Hems, R. \& Gascoyne, T. (1963b). Acta biol. med. german. 11, 607.

Krebs, H. A., Notton, B. M. \& Hems, R. (1967). Biochem.J. $101,607$.

Krebs, H. A., Speake, R. \& Hems, R. (1965). Biochem. J. 94, 712.

Mahler, H. R. (1953). Fed. Proc. 12, 694.

Miller, L. L. (1961). Recent Progr. Hormone Res. 17, 539.

Mortimore, G. E. (1963). Amer. J. Physiol. 204, 699.

Newsholme, E. A. \& Underwood, A. H. (1966). Biochem. J. 99, $24 \mathrm{c}$.

Peters, J. P. \& Van Slyke, D. D. (1946). Quantitative Clinical Chemistry, pp. 20, 141. London: Baillière, Tindall and Cox.

Ross, B. D., Hems, R. \& Krebs, H. A. (1967). Biochem. J. $102,942$.

Sokal, J. E., Miller, L. L. \& Sarcione, E. J. (1958). Amer. J. Physiol. 195, 295.

Sokal, J. E., Sarcione, E. J. \& Henderson, A. M. (1964). Endocrinology, 74, 930.

Sokal, J. E. \& Weintraub, B. (1966). Amer. J. Physiol. 210, 63.

Struck, E., Ashmore, J. \& Wieland, O. (1965). Biochem. Z. 343, 107.

Struck, E., Ashmore, J. \& Wieland, O. (1966). In Advances in Enzyme Regulation, vol. 4, p. 219. Ed. by Weber, G. London: Pergamon Press Ltd.

Underwood, A. H. \& Newsholme, E. A. (1966a). Biochem. J. 95, 767.

Underwood, A. H. \& Newsholme, E. A. (1966b). Biochem.J. 95, 868.

Utter, M. F. \& Keech, D. B. (1963). J. biol. Chem. 238, 2603. Williamson, J. R., Wright, P.H., Malaisse, W. J.\& Ashmore, J. (1966). Biochem. biophys. Res. Commun. 24, 765. 